Egypt. Acad. J. Biolog. Sci., 4(1):55-62 (2012)

Email: egyptianacademic@yahoo.com

Received: 15/3/2012
C. Physiology \& Molecular Biology

ISSN: 2090-0767

www.eajbs.eg.net

\title{
Comparison of phylogenetic analysis in the natural salmonids by using growth hormone (GH) gene
}

\author{
Abolhasan Rezaei \\ Department of Genetics-School of Basic Science, Tonekabon Branch, Islamic Azad \\ University, Tonekabon, Iran \\ Mailing Address: Islamic Azad University Tonekabon Branch,Iran. P.O. Box 4864161187, Tonekabon, Iran.
}

\section{a.rezaei@tonekaboniau.ac.ir}

\begin{abstract}
To days, The Growth hormone (GH) gene is more important in the regulator of metabolism, osmoregulation, reproduction and skeletal growth in Livestock. GH almost in all of animals has been same function that mentioned. This hormone also is exciting skeletal cellular for more growth and replication. In Salmonids for specially, furthermore, GH gene in population of salmonids can be used as the studies of phylogenetics and finding ancient and pedigree of salmonids that some researchers used from GH gene in salmo salar and salmo trutta for studies of phylogenetics. In this study we had done sequence of fragments of GH gene in salmo trutta caspius full length of almost 2048 bp. and deposited in GeneBank (accession number, JN24163) For sequencing of GH gene in the Salmo trutta caspius, first was extracted DNA genomics from bloods and the muscles of salmons, in related to, we designed three pairs of primers from first to end of the GH gene in same sequences from salmo salar and salmo trutta that reported in GeneBank. After sequencing of fragments we analyzed fragments and compared with other sequences in salmonid fishes. In this research our aims, study of amount variation in the between salmo trutta caspius species with Atlantic salmon and also, study amount of phylogenetic variation between Salmo trutta caspius with other salmons regarding to the GH gene.
\end{abstract}

Keywords: Salmo trutta caspius, sequencing, Phylogenetic analysis, growth hormone gene

\section{INTRODUCTION}

Growth hormone (GH) gene has been very benefits in natural salmonids. To increase of body composition, health, milk production, aging and other same functions is important in GH gene (Lincoln et al., 1995; Cook et al., 2000; Devlin et al., 2004). The growth hormone receptor on target cells by transducting the myogenic stimulating signal across the cell membrane and inducing the transcription of many genes, including IGF-I (Rotwein et al., 1994).The GH gene however effective on the cell growth rate, but also, it has been other function for polymorphism of populations in animals. GH gene in bovine changed a single nucleotide polymorphism in fifth exon (Lucy et al.,
1991; Zhang et al., 1992;Yao et al., 1996). The many genes were used for polymorphism of salmonids, mitochondrial DNA has been studied extensively in numerous fish species by restriction site analysis of the entire mitochondrial genome or by 'micro restriction' mapping and direct sequencing of the selectively amplified genes (Beckenbach, 1991; Bernatchez et al., 1992; Whitmore et al., 1992; Ovenden et al., 1993), that used some genes for this means, including, cytochrome b gene in salmo treutta fario (Rezaei and Akhshabi, 2012), cytochrome b in salmo trutta caspius (Jamshidi and Kalbasi, 2009), and other genes in mitochondrial DNA. The mitochondrial DNA more inherited 
maternal traits than paternal traits,but in GH gene more inherited paternal trait on the nuclear DNA genomics. GH gene in salmonids have is duplicated because tetraploids origin and as a consequence, two forms of GH are produced. (Agellon et al., 1988; Rentier-Delrue et al., 1989). The GH sequence in teleost species have recently cloned, such as goldfish (Carassius auratus) (Lee et al., 2001), turbot (Scophthalmus maximusi) (Calduch-Giner et al., 2001), Japanese eel (Anguilla japonica) (Ozaki et al., 2002), black seabream (Acanthopagrus schlegeli) (Tse et al., 2003), rainbow trout (Oncorhynchus mykiss) (Very et al., 2005) and gilthead seabream (Sparusaurata) (Calduch-Giner et al., 2003; Saera-Vila et al., 2005). In natural salmonids, including, salmo salar, salmo trutta and salmo trutta caspius, GH gene investigated for comparison of phylogenetics and the relationship between ancient of natural salmonids. In this study we analysed the among of variation and relationship between natural salmons by using GH gene that other researchers used this gene for polymorphism of populations salmonids.

\section{MATERIALS AND METHODS}

Samples Fishes: The adult fishes including male and female salmon was caught from muscles and bloods for DNA extraction. These salmons had 2-3 years old age that originated from the Rivers of Sardabrood and Dohezar of Tonekabon-Iran.

DNA extraction: DNA extracted by kit (produced by Chromous Company kit, Bangalore-India) was used from 2-3 grams muscles and also 1 cc bloods. The salmons were caught after anesthetic of that, samples were muscle fins and also blood. These samples immediately had cold on the temperature of $20^{\circ} \mathrm{C}$ for next experiments.

Primers: Three pairs of primers were designed according to method of designing primers by DNAMAN program computer and also BLAST network system. In this regards, we used some GH gene that reported in GeneBank including, salmo salar and salmo trutta, because we assumed these sequences had high homology with salmo trutta caspius. The fragment of primers including:

Product Size 1495 bp.

Primer_Set_I_For.

AATCATCCTTGGCAATTAAGAG

Primer_Set_I_Rev.

CCTTAGTTGAAGGCACTGAGGT

Product Size 1500 bp.

Primer_Set_II_For.

GCATGTTATGCCCTTTAAAACC

Primer_Set_II_Rev.

CAGTCCTGTGGCCTTCAAGT

Product Size 1493 bp.

Primer_Set_III_For.

TGAACTCAAAGTCAATGAAAAGTCA

Primer_Set_III_Rev.

AACCCTGGAGACAGGCTCTT

PCR Amplification: Different set of parameters (Gradient Cycle, Primer Concentration variation, Magnesium Chloride variation, PCR Cycle variation) have been set to standardize the PCR amplification of DNA with above primer sets. PCR was performed using primers (PCR cycle conditions are mentioned below), including:

Template DNA: $\quad 1.0 \mu \mathrm{l}$

Forward primer $(100 \mathrm{ng} / \mathrm{ml}) \quad 2.0 \mu \mathrm{l}$

PCR Cycle condition:

\begin{tabular}{|c|c|c|c|c|}
\hline $94^{\circ} \mathrm{C}$ & $94^{\circ} \mathrm{C}$ & $55^{\circ} \mathrm{C}$ & $72^{\circ} \mathrm{C}$ & $94^{\circ} \mathrm{C}$ \\
\hline $5 \mathrm{~min}$ & $30 \mathrm{sec}$ & $30 \mathrm{sec}$ & $1 \mathrm{~min}$ & $5 \mathrm{~min}$ \\
\hline & \multicolumn{3}{|c|}{35 cycles } & \\
\hline \multicolumn{4}{|c|}{ Reverse primer (100ng/ ml) } & $2.0 \mu \mathrm{l}$ \\
\hline \multicolumn{4}{|c|}{ dNTP mix (2.5mM each) } & $2.0 \mu \mathrm{l}$ \\
\hline \multicolumn{4}{|c|}{ 10X ChromTaq Assay buffer } & $5.0 \mu \mathrm{l}$ \\
\hline \multicolumn{4}{|c|}{ ChromTaq enzyme (3U/ ml) } & $0.5 \mu \mathrm{l}$ \\
\hline \multicolumn{4}{|c|}{ Water: } & $37.5 \mu \mathrm{l}$ \\
\hline \multicolumn{4}{|c|}{ Total Reaction volume: } & $50.0 \mu \mathrm{l}$ \\
\hline
\end{tabular}

Electrophoresis: Amplified GH gene full length was separated by one percent agarose gel electrophoresis. Gels were loaded at approximately $100 \mathrm{~V}$ until the Bromophenol blue dye front reached the 
end of the gel. After electrophoresis, the DNA full length was visualized ethidium bromide and then was taken photos by gel DOC Bio RAD Company.

GEL Extraction and PCR purification by the kit SPIN-50 (RKT33): The kit is designed for rapid purification of plasmid DNA from standard or low-melt agarose in TAE or TBE solution. Features of the kit: High quality DNA and no phenol chloroform required. PCR products were gel eluted and sequenced using gene specific forward and reverse primer. Finally, the PCR products were sent to the Choromous Geni CompanyIndia for doing sequencing.

Sequencing of fragments: Fragments of GH gene were amplified, these fragments the was loaded on the gel electrophoresis, first, purified by extraction of gel electrophoresis kit by method of mentioned: A. Cut the DNA fragment from the Agarose gel with a clean, sharp cutter. B. Weigh the gel slice in a $2 \mathrm{ml}$ micro centrifuge tube $\mathbf{C}$. Add 3 volumes of Gel extraction buffer to 1 volume of gel (100mg) C. Incubate the tube at $55^{\circ} \mathrm{C}$ for 5 10 min (or until the gel piece has completely dissolved). Mix the sample by inverting the tube every 2-3 min during the incubation to solublize agarose completely. For $>2 \%$ agarose gels, increase the incubation time. D. After the gel piece has dissolved completely, add 1 gel volume of isopropanol to the tube and mix (If the Agarose gel piece is $100 \mathrm{mg}$, add $100 \mu \mathrm{l}$ isopropanol). E. Place the spin column in a $2 \mathrm{ml}$ collection tube provided. F. Load the gel extracted solution mixed with isopropanol on to the spin column (6000g for each time). G. Spin at 13,000g for $1 \mathrm{~min}$ at Room Temperature. Discard the contents of the collection tube. Place the spin column back in the same collection tube. H. Add $500 \mu \mathrm{l}$ of wash buffer to the column. Spin at 13,000g for 1

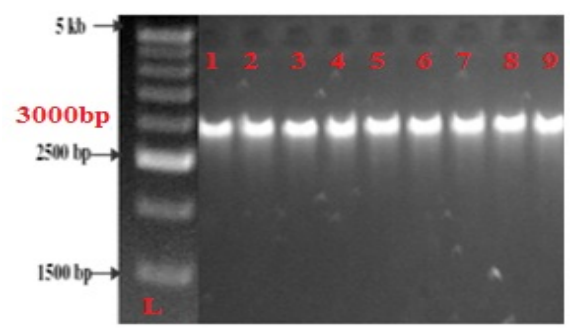

Fig. 2: PCR amplification of Growth hormone gene $(\sim 3 \mathrm{~kb})$ Salmo trutta caspius from samples 1 to 9. PCR Products were loaded on $1 \%$ agarose gel. L: 500bp DNA ladder. min at room temperature. Discard the contents of the collection tube. Place the spin column back in the same collection tube. $\mathbf{K}$. Repeat step 9. L. Spin the empty column with the collection tube at $13000 \mathrm{~g}$ for $3 \mathrm{~min}$ at RT. M. Place the spin column in a fresh $1.5 \mathrm{ml}$ micro centrifuge tube. $\mathbf{N}$. Add $15 \mu \mathrm{l}$ of Elution Buffer on to the spin column. O. Keep the vial along with the spin column at Room temperature for $2 \mathrm{~min}$. Z. Spin at $13,000 \mathrm{~g}$ for $1 \mathrm{~min}$ at room temperature. $\mathbf{P}$. Again add $15 \mu \mathrm{l}$ of Elution Buffer on to the spin column. Q. Keep the vial along with the spin column at Room temperature for $2 \mathrm{~min}$. Spin at $13000 \mathrm{~g}$ for $1 \mathrm{~min}$ at room temperature. R. Purified DNA is collected in the tube. DNA purified after were dried and ready for sequencing by primer walking.

Designing of primer: A fragment of DNA were designed from end of DNA for amplify of DNA sequences. Including, ATCTGGTAGAGCCTGACTCCA

\section{RESULTS}

Study variations at DNA level contribute to the genetic characterization of Salmons we used GH of gene. According to the annotation $\mathrm{GH}$ genes, these are genes linked to economic traits and polymorphism genetics which are governed by many genes, following to the sequences of the salmon $\mathrm{GH}$ gene were published in the BLASTn on the National Centre for Biotechnology Information (NCBI) Network Service, was designed a fragment of almost 3kb. Hence, genomic DNA was extracted from blood samples salmo trutta caspius (Fig. 1).

PCR amplification gel photo: According to reported sequences about GH genes at NCBI network, we have expected full length almost $3.5 \mathrm{~kb}$ from PCR products but are shown approximately $3 \mathrm{~kb}$ from full length salmo trutta caspius (Fig. 2).

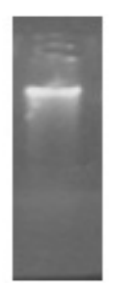

Fig. 1: Genomic DNA was extracted from blood sample Salmo trutta caspius was loaded on $1 \%$ agarose gel. 
Exons highlighted in the reference sequence:

GATCTAATGTGTTATATTCGCCTACATTACTTTCACATTTCCACAAACTCCAAAGTATTTCCTTTCAAATGGTATCA ATAATATGCATATCCTTGCTTCAGGTCCTGAGCTACAGGCAGTTAGATTTGGTTATGTCATTTCAGGTGAAAATTGG GAAAAAAAGGGTCCGATCCTTAAGAGGTTTTAATGCCATAGGACATTCAATTTGACAATAAACAATAAAATATTG GTGCTGATAAAGAAGCAATATAATACATTTGTCAAATACTGCATGTTATCTACAGTACCACAGGTGGAATGGCAG AATAACCGGTGTTGTGTGTGTATGTGTGTGTGTAACTTGTGTCCATTCATTACATCCTAGACAACAGAGGTTTGTGT TGTGTTTTGACCCTAATTCGTTCAGTCATCAAGTAAGTTGTTTTTTAGGACACGTCCCCTCTTCCAAACTCATGGAA AAATGTAGGATTGATTTGACGCATTATAGTGATTGTTCCACAATCACATACAAAAACAGGTCCTATTAATGAAAGG TGGTAAATGGATGAAAATCTCATGTTTCCTCCTGGTGATACATTAAAACATGGGTTCCCCATCTATAAAAACAGTG GTCCCAAACAAACAGCAACATACTCAACCGACCACCGCACTTTCAAGTTAAGTAATCATCCTTGGCAATTAAGAGT AAAAATGGGACAAGGTAAGCCTGCTTTTTCTGTCTATTTCTTTTTTCAGTGGGAAGTCAGTGTACCATTTAGTACAA TTTAACTTACACATTTAATCACTGAGGCAGGGGCCAACACGGCAGAGAAAAGTGAACAAGTATTCTACTACTATG AGGTTATAAATCTATTGACACAGAACCACCTGCTTTAACAACCTAACTATGTGATCTATAACATTTACATTTGAGTC GTTTAGCAGACGCTCTTATCCAGAGCGACTTACAGGAGCAATTAGGGTTAAGTGCCTTGCTCAAGGGCACGTCGAC AGATTTCTCACCTAGTCAGCTCAGGGATTGAAACCAGTAACCTTTCAATTACTTACCCAACGCTCTTAACCGCTAG GCTATTGGTGTTCGATGGCTGAGAATATCTAACTAATGTATCTCACCATAATTCGACTTACTCGTTTTATACATTTG TTATTTTCTCTTTCTTTTAGTGTTTCTGCTGATGCCAGTCTTACTGGTCAGTTGTTTTCTGAGCCAAGGGGCAGCGAT GGAAAACCAACGGCTCTTCAACATCGCGGTCAACCGGGTGCAACATCTCCACCTAATGGCTCAGAAGATGTTCAA TGACTTTGTAAGACAGCTTTTGAATCTTCTTTTGACATATCAAATAGTGTATCAATGATGTTCTTCTTCTTGTAGAC AGTGTCCTCTTTACACAACCCTCGTGGCAACAACAAAAAAATCTCTCTCCCTTCTTTGTGATTTTGTGCAGGAAGGT ACCCTGTTGCCTGATGAACGCAGACAGCTGAACAAGATATTCCTGCTGGACTTCTGTAACTCTGACTCCATCGTGA GCCCAATCGACAAGCTTGAGACTCAGAAGAGTTCAGTAAGTAACCTGGTTGAGACAATTATGCATGTTATGCCCTT TAAAACCATATAAAAGTGTAAAATTGTGACAGGTCCACTCTGCTATTCACCTTAAATATGAATTCCTCCATGATGC ATGATTCCAAAATAAATAATATGGCATCTCAATTTGAACAATCGATAGAACTTAGTCATTAGTTATTGGGAAAGCA GACCACCAATTATCTAAACTCCAATTTATAAATGTTTTAATTTGAATTTTTTTACCATTATTTAACTAGGCAAGTCA ATTAAGAACAAATTCTCATTTACAATGACAAGCAGAGGCTGCATCATGCATGGCTGTCGAGTGGCGCACGAGTCT AAGGCACTGCATCTCAGTGTTAGAGGTGTCACTACAGACCCTGGTTCGATTCCAGACTGTATTACAAATGGCTGTG ATTGGGAGTCCCATAGGCGACACGCAATTGGCCCACCGTCGTTAGGGTTTGGCCGGGGTTGGCGGTCAAATAAAA AAAAAATGGTGGAAATGAAATCTAGCCATGACAGAGAGTTTAACTGTACATGTAAAATTGGCATTAACACATTGC TATACCTCAGTGCCTTCAACTAAGGTAGGTAAAACAACCACATATCAAAGTCATTGCAAGTAAAACCATCACTCTC TAAATCGGTGGTTTCTCTACGTCTACATTCTCCGTTTTGTGCTTTTCTGTCCAGGAAACCAGCCCCAAAGGTTTTTA ACTCAATCATGTAAATAGGGAATCTCAAGCTGTACAATACAACGCAACTTCATTTTCCAATAATCTGTGGTTTCTCT ACATCTACACACACCACAGGTCCTGAAGCTGCTCCATATCTCTTTCCGTCTGATTGAATCCTGGGAGTACCCTAGCC AGACCCTGACCATCTCCAACAGCCTAATGGTCAGAAACTCCAACCAGATCTCTGAGAAGCTCAGCGACCTCAAAG TGGGCATCAACCTGCTCATCAAGGTAAAGAAAGGAGGGAGAACAATGACCATTTGTGGTGCCACACTTTGTGCAC TGTAAACCCCAAGGCATTTTTAACTCAAATACTTCTAGTAAGTTGAACTCAAAGTCAATGAAAAGTCATTATTACT TAAAATGTTTATGTGGTACTGGCTCAAAACTAAATGAGAAGTGACATCAACACAATTTTTTAAAGTTATAACAAAT TAACTTTTTATCCAGCATGCTCTACTGCAGGTAGATTTTTTGGAATTGTTTTTAACTATCTGTGTTTTGCATGTACAG GACATTGAGTGATTGATTCATCGTATGCTACACAAAGATATATAACATACATTTTTCAACATTTTCACAAAGATGA ATAAGTTACCAGAATTTTGCAAACCCGACTTGCAGGCCTGATGTGGCCTTAAACTATGAGTTTCAGGCCACTGTAT TAGGGTACACGTACGCCTCAAAATACGGTCTTATGAGATATGTAATGTATTGTTATAAAGAGTTGAATTACAATGA TAATATTTGCCTAGGAATTAACTTGAAGGCCACAGGACTGAAAATGAATGACAACCATGTCTCTGTTACTAACAAA TACAGTCATGGGTGATAACTACAATTCACTCAAAAAGGCCAGGCACACTGGGAAATGATATTGGGGACGTGGCTT AGTGAGGGCATTACTAAAAAATGTCAAGCTGATACAACTCAAATCTGGACCCTTCACAGGGTGACTAGAGTAATG ACTAACTGCAGTCAGATTCTATATATTAAGTGCAACGGGTTTCCTAAAACGTTTTGAGTAATGACAGCACATTGGG TTTTACAGTGACATGAAAGTGAAATACCTCTATGCTTTCCTAGTTAGAAAGCATAGTGTAGGACCACGTTTGCCTC TTCTCAGCAGATCTTTCAGTGCTTTACATTGTGATGGGGTAAATAACCTCATCTATCATCACTAATATTGACTATAT CAGTAACACCCCATTCAATGACTGAATATCAGCCCATTCAAGGATATTTATGCATGCGTCTTTTGCTGTGTGTGCTT TCAGAAAGGCCCAATAAACAAATATTGATATGCACACATCCACCCСACCATGCATCTCTCTCTGTCTCCCACAGGG GAGCCAGGATGGCGTACTGAGCCTGGATGACAATGACTCTCAGCAGCTGCCCCCCTACGGGAACTACTACCAGAA CCTGGGGGGCGACGGCAACGTCAGGAGGAACTATGAGTTGTTGGCCTGCTTCAAGAAGGACATGCACAAGGTGCA AAACCATGTTGCCTTCTATTTCATGTGCCTTCCTATATTTTCTACAGTGCGTTTCTTGTGCTCTCTATTGCAAAGTAT CTTTGGGTCTTTAACCCATATATTATTACTATTATTGTTCATTGATCAAGACTGTTCTCGAGAAAGGTCTAGTGACC TAGAACACTCACATTAAAATGTGTCAACTATAACCCATTCTTCTATTTTTCCCCCAAGGTCGAGACCTACCTGACCG TCGCCAAGTGCAGGAAGTCACTGGAGGCCAACTGCACTCTGTAGACGTGGGCTGGAGAGGCAGCCAGCAAGAGCC TGTCTCCAGGGTTCGGTTTCCCAGATACAGATTAGGCCTTGCCCTGCACTGAAGAGCATTTTCAATTGAGATTCTCC ATTAAACGTGCTTTTTAGTCTAGAGTAGATTTAATTTGGATCTGGTAGAGCCTGACTCCAGGGGTTTTCAGGAATTT GCATTTTGTTCTCTGAAATCAACAACAGCACTTTCTATATTGACT

Fig. 3: Yellow: Exons, Green: Primers designed for amplification of GH gene in salmo trutta caspius that originated from Salmo salar sequence of GH gene had reported in GeneBank, Blue: primer designed for sequencing and amplification

\section{DISCUSSION}

The family Salmonidae comprises eleven genera and includes salmon, trout, charr, freshwater whitefishes, ciscos and graylings (Nelson, 2006). Many salmonid species are of considerable genetics polymorphism, economic, social and environmental importance. Many genes engaged on the growth cells, metabolism and anabolism in the natural salmonids, 
specially GH gene. This gene has two types, type I and type II. (Agellon et al., 1988 and 1989; Rentier-Delrue et al., 1989). The growth hormone gene in teleost (Siluriforms and Cypriniforms) which consist of the five exon type and four intron type, while in salmoniforms, Perciforms and Tetradontiforms, which consist of six exons and five introns (six exon type) (Moriyama et al., 2006). There are some genes that finding ancestral of salmonids, these genes including, mitochondrial genomics that more inherited of maternal traits (Allendorf et al., 1984; Bernatchez et al., 1992; Bernatchez, 1995), and GH gene that inherited of paternal traits (Gross and Nilsson, 1995). The aim of this study was to annotate the coding sequence of the $\mathrm{GH}$ gene and perform a GH-based phylogenetic analysis within the salmonids family. The GH gene as a natural marker for studies of evolutionary genetics of various fishes because of its sequence conservation, in salmonids (Marins et al., 2003; Chen et al., 2004; Pinheiro et al., 2008). According those results, The salmo trutta caspius possible has been ancestral with salmo salar,salmo trutta and homology with onchorhyncus mykiss and chun salmon. The analysis and sequenced provided valuable information about the mode of evaluation of these DNA sequences. In this project we analyzed the rate of homology between population salmonids by GH genes, there were some documents that they are alleles at a common ancient, from 12000-14000 years ago. Berg et al., (1962) proposed that salmo trutta had originated from Atlantic Ocean that had been migrated to White Sea and then left to Russia in Caspian Sea. Also they proposed that these salmons is related to deep, and the rivers of around Caspian Sea is very good for passing period of smolt and egg laid by adult salmons those will select the rivers of connected to Caspian Sea, in fact these results introduced and denoted that salmo trutta caspius can be originated from Atlantic salmons.

The phylogenetic tree: The evolutionary hypothesis of a phylogeny can be graphically represented by a phylogenetic tree. The neighbor joining algorithm, (Saitou and Nei, 1987), on the other hand, builds a tree where the evolutionary rates are free to differ in different lineages.

The same results phylogenetic tree in figure 4 and figure 5, are shown that denoted and annotated, salmo trutta caspius, salmo salar, salmo trutta, onchorhyncus mykiss, and other salmonids had common ancient according hypothesis by Berg, 1962. In figure 4 distance of between salmo trutta caspius with salmo salar is longer (74 to $89 \%$ ) than rainbow trout (94\%), however for generally distance genetics between sequences of GH gene is not very long and among of homology is very high.

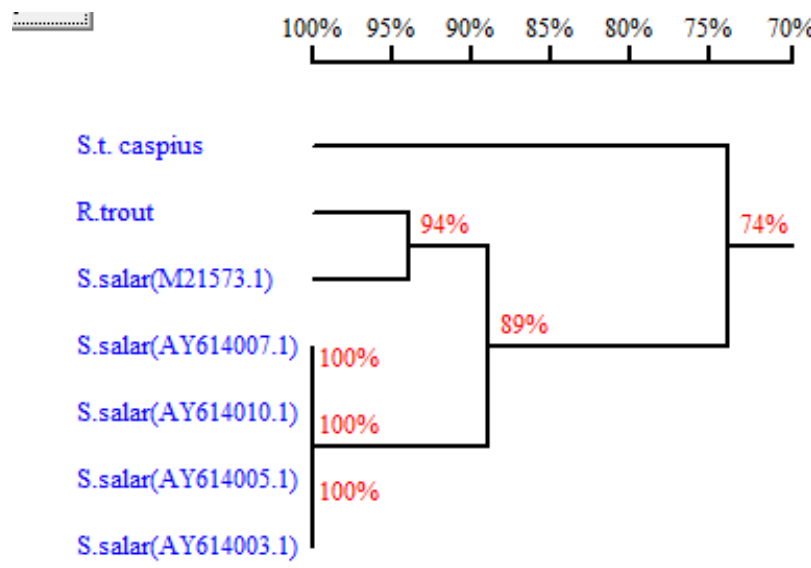

Fig. 4: Results of phylogenetic analysis sequences of the GH gene in salmo trutta caspius and Rainbow trout, Salmo salar(different sequences that reported in GeneBank). The consensus tree is shown 
obtained high homology between sequences, however in salmo trutta caspius the rate of homology less than other salmons. These results obtained from DNAMAN computer program.

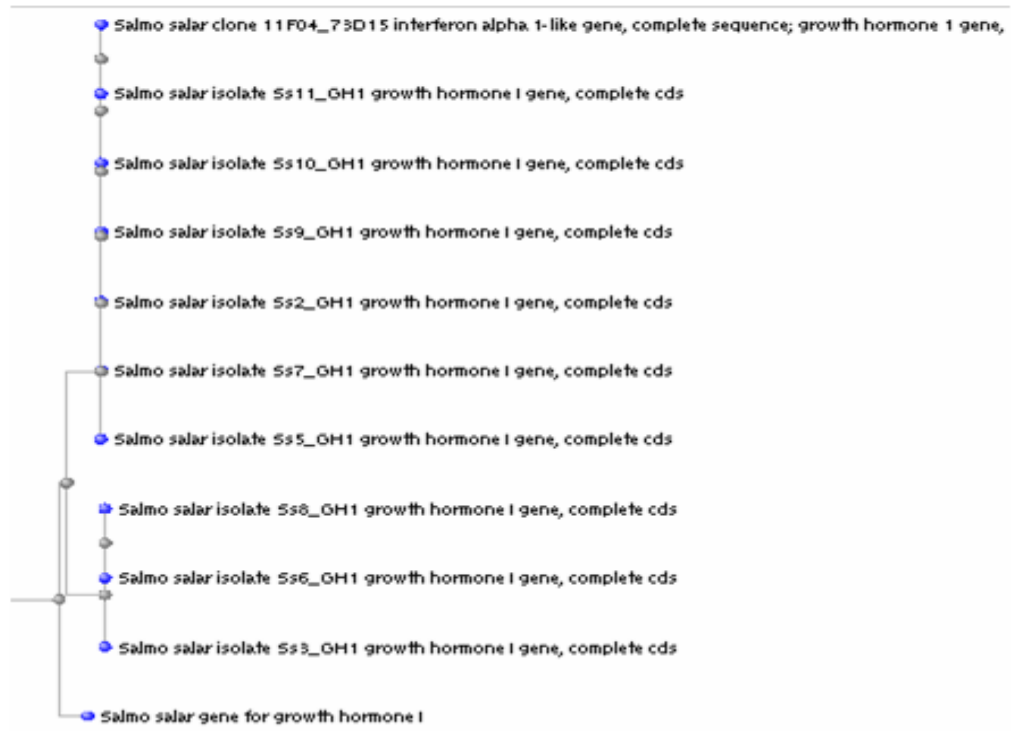

S salmo trutta caspius growth hormone gene, complete cds

Fig. 5: Results of phylogenetic analysis sequences of the GH gene in salmo trutta caspius and Salmo salar(different sequences that reported in GeneBank). The consensus tree is shown obtained high homology between sequences, however in salmo trutta caspius the rate of homology less than other salmons. These results obtained from BLAST NCBI Network program.

\section{CONCLUSION}

In this study we shows in salmo trutta caspius $\mathrm{GH}$ gene can be marker genetics for analysis of polymorphism populations in salmons. However the among of homology in GH gene denote for finding of pedigree is good but also these gene more inherited paternal traits to offspring, so we proposed that use other gene from mitochondrial genomics that inherited maternal traits and also microsatellites fragments in length of DNA genomics, with compare these information finally we can surely analyse phylogenetic populations of salmonids, however information of $\mathrm{GH}$ gene are very benefit for evolutionary and also finding ancestral of population salmons.

\section{ACKNOWLEDGMENTS}

This work had financially supported by the Research Council of Islamic Azad University Tonekabon Branch. IRAN.

\section{REFERENCES}

Agellon, L.B., Davies S.L., Chen T.T. and Powers D.A. (1988): Structure of a fish (rainbow trout) growth hormone gene and its evolutionary implications. Proc. Natl. Acad. Sci. U.S.A. 85:5136-5140.

Agelon, L. B. (1998): Promotion of rapid growth of rainbow trout (Salmo gairdneri) by a recombinant fish growth hormone; Can. J. Fish. Aquat. Sci. 45:146-151.

Allendorf, F.W. (1984): Thorgaard GH: Tetraploidy and the evolution of salmonid fishes. In Evolutionary Genetics of Fishes. Edited by Turner, B.J. New York: Plenum Press. 1-53.

Bernatchez, L., Guyomard, R. and Bonhomme, F. (1992): DNA sequence variation of the mitochondrial control region among 
geographically and morphologically, remote European brown trout Salmo trutta populations. Molecular Ecology. 1: 161 -1 73.

Bernatchez, L. Osinov, A. (1995): Genetic diversity of trout (genus Salmo) from its most eastern native range based on mitochondrial DNA and nuclear gene variation. Molecular Ecology. 4: 285-297.

Beckenbach, A.T. (1991): Rapid mtDNA sequence analysis of fish populations using the polymerase chain reaction (PCR). Canad. J. Fish. Aquat. Sci. 48:95-98.

Berg, L.S. (1962): Freshwater fishes of the U.S.S.R. and adjacent countries, National Science Foundation, Washington D.C. Vol.,1:11.

Calduch-Giner, J.A., Mingarro, M. VegaRubín de Celis, S., Boujard, D., Pe'rez-Sa'nchez, J. (2003): Molecular cloning and characterization of gilthead sea bream (Sparus aurata) growth hormone receptor (GHR). Assessment of alternative splicing. Comp. Biochem. Physiol. B. 136 (1): 1-13.

Chen, Y., Wang, Y., Hes and Zhu, Z. (2004): Cloning and sequencing of the growth hormone gene of large yellow croaker and its phylogenetic significance. Biochem. Genet. 42: 365-375.

Cook, J. T., McNiven, M. A., Richardson, G.F.(2000): Growth rate, body composition/feed digestibility conversion of growth-enhanced transgenic Atlantic salmon (Salmo salar). Aquaculture. 188(1-2): 15-32.

Devlin, R. H., Biag., C. A., Yesaki, T. Y. (2004): Growth, viability and genetic characteristics of GH transgenic coho salmon strains. Aquacult., 236(14):607-632.

Gross, R. Nilsson, J. (1995): Application of heteroduplex analysis for detecting variation within the growth hormone 2 gene in Salmo trutta L.brown trout, Heredity.74: 286-295.
Jamshidi, S. and Kalbassi, M.R. Direct Submission Submitted., (2009): Marine Science and Fisheries,. Unpublished.

Lee, L.T.O., Nong, G., Tse, D.L.Y., Cheng, C.H.K. (2001). Molecular cloning of a teleost growth hormone receptor and its functional interaction with human growth hormone. Gene. 270: 121-129.

Lincoln, D. T., F. Sinowatz, E. elHifnawi, R. L. Hughes, and Waters, M. (1995): Evidence of a direct role for growth hormone GH in mammary gland proliferation and lactation. Anat. Histol. Embryol. 24:107-115.

Lucy, M. C., S. D. Hauser, P. J. Eppard, G. G. Krivi, and R. J. Collier. (1991): Genetic polymorphism within the bovine somatotropin (bST) gene detected by polymerase chain reaction and endonuclease digestion. J. Dairy Sci. 74(Suppl. 1):284.

Marins, L., Levy, J., Folch, J and Sanchez, A. (2003): A growth hormone-based phylogenetic analysis of euteleostean fishes including a representative species of the Atheriniformes Order, Odontesthes argentinensis. Genet. Mol. Biol. 26: 295-300.

Moriyama, S., Oda M., Takahashi, A., Sower, S.A. (2006): Genomic structure of the sea lamprey growth hormone-encoding gene. Gen. Comp. Endocrinol. 148: 33-40.

Nelson, J.S. (2006): Fishes of the World. $3^{\text {rd }}$ edition. New York: Wiley and Son.

Ovenden, J. R. Water, R. and White, R. W. G. (1993): Mitochondrial DNA nucleotide sequence variation in Atlantic salmon (Salmo salar), brown trout (S. trutta), rainbow trout (Oncorhynchus mykiss) and brook trout (Salvelinus fontinalis) from Tasmania, Australia. Aquaculture. 114: 217-227.

Ozaki, Y., Fukada, H., Kazeto, Y., Adachi, S., Hara, A., Yamauchi, K. 
(2002): Isolation of two types of cDNA encoding growth hormone receptor like gene in the Japanese eel, Anguilla japonica. In: Proceedings of international commemorative symposium, 70th Anniversary of the Japanese Society of Fisheries Science, 68 (Suppl): I.959-960.

Pinheiro, J.S., Wolff, J., Araújo, R and Hilsdorf, A. (2008): Molecular cloning and sequence analysis of growth hormone cDNA of Neotropical freshwater fish Pacu (Piaractus mesopotamicus). Genet. Mol. Biol. 31: 381-384.

Rezaei, A. and Akhshabi, S.H. (2012): Evolutionary Genetic Analysis of the cytochrome b gene variation in the Salmo trutta fario with other salmons. Egypt. Acad. J. Biolog. Sci., 3(1):65-71.

Rentier-Delrue, F., Swennen, D., Mercier, L., Lion, M., Benrubi, O., Martial, J.A. (1989): Molecular cloning and characterization of two forms of trout growth hormone cDNA: expression and secretion of tGH-II by Escherichia coli. DNA (N.Y.). 8: 109-117.

Rotwein, P., A. M. Gronowski and Thomas, M.J. (1994): Rapid nuclear actions of growth hormone. Horm. Res. 42:170-175.

Saera-Vila, A., J.P. Calduch-Giner and J. Pe'rez- Sa'Nchez. (2005): Duplication of growth hormone receptor (GHR) in fish genome: gene organization and transcriptional regulation of GHR type I and II in gilthead sea bream (Sparus aurata). Gen. Comp. Endocrinol. 142: 193-203.
Saitou, N. and Nei, M. (1987): The neighbor-joining method: a new method for reconstructing phylogenetic trees. Mol Biol Evol, 4(4):406--425.

Tse, D.L.Y., Tse, M.C.L., Chan, C.B., Zhang, W.M., Lin, H.R., Cheng, C.H.K.(2003): Seabream growth hormone receptor: molecular cloning and functional studies of the fulllength cDNA, and tissue expression of two alternatively spliced forms. Biochim. Biophys. Acta. 1625: 6476.

Very, N. M., Kittilson, J.D., Norbeck, L. A., Sheridan, M. A. (2005): Isolation, characterization, and distribution of two cDNAs encoding for growth hormone receptor in rainbow trout (Oncorhynchus mykiss). Comp. Biochem. Physiol. B 140: 615-628.

Whitmore, D.H., T.H. Thai, and Craft, C.M. (1992): Gene amplification permits minimally invasive analysis of fish mitochondrial DNA Transactions of the American Fisheries Society 121:170-177.

Yao, J., S.E . Aggrey., D. Zadworny, J. F. Hayes, and Kuhnlein, U. (1996): Sequence variations in the bovine growth hormone gene characterized by single-strand conformation polymorphism (SSCP) analysis and their association with milk production traits in Holsteins. Genetics 144:1809-1816.

Zhang, H. M., D. R. Brown, S. K. Denise and Ax, R.L. (1992): Nucleotide sequence determination of a bovine somatotropin allele. Anim. Genet. 23:578. 